\title{
Hematological profile of pregnant women at St. Paul's Hospital Millennium Medical College, Addis Ababa, Ethiopia
}

\author{
Angesom Gebreweld ${ }^{1 *}$, Delayehu Bekele ${ }^{2}$ and Aster Tsegaye ${ }^{3}$
}

\begin{abstract}
Background: In pregnancy, hematological changes occur in order to meet the demands of the developing fetus and placenta, with major alterations in blood volume. Abnormal hematological profile affects pregnancy and its outcome. This study aimed to assess hematological profiles of pregnant women at a tertiary care teaching hospital.

Method: This cross sectional study was conducted among 284 consecutive pregnant women at St. Paul's Hospital Millennium Medical College. Socio-demographic characteristics were collected using pre-tested structured questionnaire. About $4 \mathrm{ml}$ of venous blood was collected from each participant for hematological parameters analysis using Cell-Dyn1800 (Abbott Laboratories Diagnostics Division, USA) and peripheral blood film review.

Result: There were differences in mean hematological parameters between trimesters: specifically differences in mean values of WBC ( $1^{\text {st }}$ and $\left.3 r d\right), H b\left(1\right.$ stand $2^{\text {nd }}$ and $\left.1^{\text {st }} \& 3 r d\right), H C T\left(1^{\text {st }}\right.$ and 2 nd $)$, RDW $\left(1^{\text {st }}\right.$ and $2^{\text {nd }}$ and $1^{\text {st }}$ and $\left.3 r d\right)$, neutrophil and lymphocyte ( 1 stand 2 nd and $1^{\text {st and }} 3^{\text {rd, }}$ for both) were statistically significant $(p<0.05)$. The prevalence rates of anemia and thrombocytopenia were 11.62 and $7.7 \%$, respectively and were dominantly of mild type. On the bases of blood picture, we classified anemia's of pregnancy as microcytic hypochromic (51.5\%), normocytic hypochromic (27.3\%), normocytic normochromic (18.2\%), and dimorphic (3\%).

Conclusion: Significant changes in selected hematological parameters between trimesters, and an anemia and thrombocytopenia of mild type were documented in this study. The commonest morphologic features were mostly characteristic features of iron deficiency anemia. These warrant the need for monitoring hematological parameters of pregnant women at any stage of the pregnancy to avoid adverse outcomes.
\end{abstract}

Keywords: Pregnancy, Hematological profile, Anemia, Thrombocytopenia

\section{Background}

In pregnancy, hematological changes occur in order to meet the demands of the developing fetus and placenta, with major alterations in blood volume. The plasma volume increase by 40 to $45 \%$ on average, this increase is mediated by a direct action of progesterone and estrogen on the kidney causing the release of renin and thus an activation of the aldosterone renin-angio-tensin mechanism. This leads to renal sodium retention and an increase in total body water. This increase occurs faster in the late second trimester [1-3].

\footnotetext{
*Correspondence: afsaha@gmail.com

'Department of Medical Laboratory Science, College of Medicine and Health

Science, Wollo University, Dessie, Ethiopia

Full list of author information is available at the end of the article
}

Red blood cell mass increases by $15-20 \%$ as a result of the increase in the production of erythropoietin. As the increase in red cell mass is relatively smaller than that of plasma volume, the net result of hemoglobin $(\mathrm{Hb})$ concentration falls by $1-2 \mathrm{~g} / \mathrm{dl}$. This is termed the physiological anemia of pregnancy $[3,4]$.

In pregnancy, the peripheral blood count of white blood cell (WBC) is raised due to pregnancy induced physiological stress. Neutrophils contribute most to the overall higher WBC count. [5]. However, the platelet count decreases during pregnancy because of hemodilution, increased platelet activation and consumption, particularly in the third trimester $[4,5]$.

(C) The Author(s). 2018 Open Access This article is distributed under the terms of the Creative Commons Attribution 4.0 International License (http://creativecommons.org/licenses/by/4.0/), which permits unrestricted use, distribution, and reproduction in any medium, provided you give appropriate credit to the original author(s) and the source, provide a link to the Creative Commons license, and indicate if changes were made. The Creative Commons Public Domain Dedication waiver (http://creativecommons.org/publicdomain/zero/1.0/) applies to the data made available in this article, unless otherwise stated. 
Although physiological in nature, abnormal hematological profile affects pregnancy and its outcome. One of the most important underlying cause of maternal mortality is due to underlying hematological complications. Anemia and thrombocytopenia are the most frequent hematologic complications during pregnancy $[6,7]$.

Anemia of pregnancy is said to occur when $\mathrm{Hb}$ concentration is less than $110 \mathrm{~g} / \mathrm{l}$ [8], as per World Health Organization (WHO) recommendation. Global prevalence of anemia in pregnant women is $41.8 \%$. Africa and Asia are the most heavily affected regions. Throughout Africa, about $56 \%$ of pregnant women are anemic. As documented in the WHO2008 report, this hematological disorder is a severe public health problem in Ethiopian pregnant women and the estimated prevalence was $62.7 \%[9,10]$.

The functional consequences of anemia are serious and include an increased risk of maternal, fetal, and neonatal mortality. Poor pregnancy outcomes such as low birth weight and preterm birth; impaired cognitive development, reduced learning capacity, and diminished school performance in children; and decreased productivity in adults are among the consequences [11]. In neighboring Sudan, 20.3\% of maternal deaths are associated with anemia [12].

Thrombocytopenia is one of the most common hematologic abnormalities encountered during pregnancy. About $8-10 \%$ of pregnant women are affected by thrombocytopenia (platelet count $<150 \times 10^{9} / \mathrm{L}$ ), particularly in the third trimester. Approximately $75 \%$ of these cases are due to a benign process of gestational thrombocytopenia which is mild and have no significance for mother or fetus. But, in some instances, thrombocytopenia can also be associated with a complex clinical disorder such as preeclampsia and hemolysis, elevated liver enzymes, low platelets (HELLP) syndrome (20\%), or idiopathic thrombocytopenic purpura (ITP) (5\%). There can also be profound and even life-threatening results for both mother and baby [13-15].

As several studies showed pregnancy may have effect on hematological parameter and essential to monitor these parameters at any stage of the pregnancy [16-18]. This study was, therefore, conducted to assess hematological profile of pregnant women at St. Paul's Hospital Millennium Medical College, Addis Ababa, Ethiopia. The study provided information about the magnitude of anemia, morphological type of anemia, thrombocytopenia and change of hematological values at different trimesters which is important to detect hematological complication early and to administer appropriate therapy.

\section{Methods}

\section{Study design, area and setting}

A cross sectional health facility based study was conducted at St. Paul's Hospital, Addis Ababa, Ethiopia from
June to August 2014. St. Paul's Hospital Millennium Medical College (SPHMMC) is the second largest public hospital in Ethiopia, which is located in Gullele sub city in Addis Ababa and built by Emperor Haile Selassie in 1969. The hospital receives referrals from around the country and is under the guidance of the Ethiopian Federal Ministry of Health.

\section{Population}

A total of 284 consecutive pregnant women were enrolled from antenatal care clinic of obstetrics and gynecology Department of SPHMMC. Written informed consent was obtained from all. Pregnant women with bleeding problem, multiple pregnancies, Hepatitis B Virus infection, human immunodeficiency virus and less than 18 years of age were excluded from the study.

\section{Data collection}

A structured pre tested interviewer administered questionnaire (see Additional file 1) and medical records were used to collect socio-demographic and clinical data of the study participants. Venous blood specimen $(4 \mathrm{ml})$ was taken from each pregnant woman by a senior laboratory professional for peripheral blood film and complete blood count. Cell-Dyn 1800 (Abbott Laboratories Diagnostics Division, USA) hematological analyzer was used to determine complete blood count. Peripheral blood smear were prepared and stained by Wright's stain to look at morphological characteristics of anemia. The peripheral smears were examined by a senior laboratory technologist and principal investigator independently. Standard operating procedures were strictly followed in each step to maintain quality of the laboratory results.

According to WHO, Anemia of pregnancy is said to occur when $\mathrm{Hb}$ concentration is less than $110 \mathrm{~g} / \mathrm{l}$. Anemic pregnant women were further categorized as women with mild anemia, moderate anemia and severe anemia which corresponds to $\mathrm{Hb}$ value 100-109 g/l, 70-99 g/l, and lower than $70 \mathrm{~g} / \mathrm{l}$ respectively [8]. Thrombocytopenia is said to be present when the platelet count of the pregnant women is less than $150 \times 10^{9} / \mathrm{L}$. The platelet counts from 100 to $150 \times 10^{9} / \mathrm{L}$ is considered mild thrombocytopenia, levels ranging from 50 to $100 \times 10^{9} / \mathrm{L}$ are considered as moderate thrombocytopenia and levels less than $50 \times 10^{9} / \mathrm{L}$ are considered as severe thrombocytopenia [15].

\section{Data analysis}

The data was entered and analyzed using Statistical Package for the Social Science (SPSS) Version16 statistical software. Frequencies and means \pm standard deviation (SD) were used to summarize descriptive statistics. One-way analysis of variance (ANOVA) was used in the analysis to compare the hematologic values among trimesters. $P$ values $<0.05$ were considered as statistically significant. 


\section{Ethical considerations}

The study was approved by Departmental Research and Ethics Review Committee (DRERC) of the Department of Medical Laboratory Sciences, Addis Ababa University. After a letter of cooperation sent to St Paul's Hospital Millennium Medical College from the Department of Medical Laboratory Sciences the Institutional Review Board also approved the study. Then a letter informing the hospital administrators was written from the Institutional Review Board (IRB) and Permission obtained from St. Paul's Hospital Millennium Medical College to conduct the study. Individual consent was obtained before the questionnaires were administered and blood samples were collected. To ensure confidentiality, participants' data were linked to a code number. Any abnormal test results of participants were communicated to their attending physician.

\section{Results}

\section{General characteristics of the study participants}

A total of 284 pregnant women with a mean (SD) age of $27.3 \pm 4.48$ years (ranges from 18 to 40 ) were included in the study. About 170 (59.9\%) were in their third trimester, $66(23.2 \%)$ in second trimester, and $48(16.9 \%)$ in first trimester. Majority of the study groups 118 (41.5\%) were in the age range of 26-30 years and urban residents $(261,91.9 \%)$ (Table 1).

\section{Hematological profiles of the study participants}

The overall mean (SD) of selected hematological parameters for the study participants were as follows: WBC count $7.93 \pm 2.68 \times 10^{9} / \mathrm{L}, \mathrm{RBC}$ count $4.58 \pm$ $2.34 \times 10^{12} / \mathrm{L}, \mathrm{Hb} 130.1 \pm 16.4 \mathrm{~g} / \mathrm{L}, \mathrm{HCT} 40.07 \pm 4.15 \%$, MCV $90.60 \pm 6.59 \mathrm{fL}, \mathrm{MCH} 29.32 \pm 2.72 \mathrm{pg}, \mathrm{MCHC}$ $32.33 \pm 1.35 \%$, and PLT $249.36 \pm 80.08 \times 10^{9} / \mathrm{L}$ (Table 2).

When analyzed by trimester, the mean (SD) WBC values for the respective first, second and third trimester pregnant women were $7.02 \pm 2.61,7.83 \pm 2.62$, and $8.22 \pm 2.68\left(\times 10^{9} / \mathrm{L}\right)$, respectively. The difference was statistically significant between those in $1^{\text {st }}$ and $3^{\text {rd }}$ trimester $(P<0.05)$.The Mean $\mathrm{Hb}$ value of pregnant women in first trimester $(136.5 \pm 15.9 \mathrm{~g} / \mathrm{l})$ was significantly higher compared to those in second trimester $(126.2 \pm 17.2 \mathrm{~g} / \mathrm{l})$, and in third trimester $(129.7 \pm 15.8 \mathrm{~g} / \mathrm{l})$. Mean HCT value in the three pregnancy groups were $41.59 \pm 4.47$, $38.92 \pm 4.47$, and $40.08 \pm 3.79$ (\%), with a statistically significant difference between those in $1^{\text {st }}$ and $2^{\text {nd }}$ trimesters $(P<0.05)$. Whereas the mean red cell indices (MCV, MCH and MCHC) and mean PLT values did not differ between the three trimester groups (Table 2).

Moreover, the mean RDW values of those in the $2^{\text {nd }}$ and $3^{\text {rd }}$ trimesters are higher than those in the $1^{\text {st }}$ trimester. The neutrophil counts also follow the same increasing pattern while the lymphocyte counts in the
Table 1 Characteristics of Pregnant women $(N=284)$ at St. Paul's Hospital Millennium Medical College Addis Ababa, Ethiopia, June to August 2014

\begin{tabular}{llll}
\hline Variables & & Frequency & Percentage (\%) \\
\hline Age group (years) & $\leq 20$ & 16 & 5.6 \\
& $21-25$ & 93 & 32.7 \\
& $26-30$ & 118 & 41.5 \\
& $31-35$ & 43 & 15.1 \\
& $\geq 36$ & 14 & 4.9 \\
Occupation & Farmer & 16 & 5.6 \\
& Housewife & 164 & 57.7 \\
& Government & 24 & 8.5 \\
Educational status & Student & 8 & 2.8 \\
& Private & 72 & 25.4 \\
& Elementary & 115 & 14.8 \\
& Secondary & 54 & 19.0 \\
& Preparatory & 23 & 8.1 \\
Trimester & University/college & 50 & 17.6 \\
& Rural & 23 & 8.1 \\
& Urban & 261 & 91.9 \\
Residence & 2st trimester & 48 & 16.9 \\
& 2nd trimester & 66 & 23.2 \\
& 3rd trimester & 170 & 59.9 \\
\hline
\end{tabular}

$2^{\text {nd }}$ and $3^{\text {rd }}$ trimesters group are significantly lower than those in the 1st trimester $(P<0.05)$ (Table 2).

\section{Hematological abnormalities}

Using the WHO criterion of $\mathrm{Hb}<110 \mathrm{~g} / \mathrm{dl}$ as indicative of anemia, $33(11.62 \%)$ pregnant mothers were anemic. Of them, 23 (69.70\%) were mildly anemic (Table 3). Based on RBC morphologic classification of anemia, most of the anemic pregnant women had microcytic hypochromic 17 (51.5\%) type of anemia (Fig. 1).

Thrombocytopenia (Platelet count $<150 \times 10^{9} / \mathrm{L}$ ), was detected in 22 pregnant women giving a prevalence of $7.7 \%$. Among them, most 20 (90.91\%) were mildly thrombocytopenic (Table 4). The prevalence of thrombocytopenia was 4.2, 6.1 and $9.4 \%$ at first, second and third trimester groups, respectively (Table 5).

\section{Discussion}

The study reported herein aimed to determine the hematological profile of pregnant women visiting St. Paul's Hospital Millennium Medical College in Addis Ababa from June to August 2014.

The progressive increment of WBC from those in their first $(7.02 \pm 2.61)$ to those in their third $(8.22 \pm 2.68)$ trimester and the dominance of neutrophil in our study 
Table 2 Hematological Profiles of pregnant women based on trimesters (Mean \pm SD) in St. Paul's Hospital Millennium Medical College Addis Ababa, Ethiopia, June to August 2014

\begin{tabular}{|c|c|c|c|c|c|c|c|}
\hline \multirow[t]{2}{*}{ Parameters } & \multicolumn{4}{|l|}{ Trimester } & \multicolumn{3}{|l|}{$P$-Value } \\
\hline & Overall & $1^{\text {st }}$ trimester $\mathrm{PW}$ & $2^{\text {nd }}$ trimester $\mathrm{PW}$ & $3^{\text {rd }}$ trimester $\mathrm{PW}$ & $1^{\text {st }} \& 2^{\text {nd }}$ & $1^{\text {st }} \& 3^{\text {rd }}$ & $2^{\text {nd }} \& 3^{3 r d}$ \\
\hline$\overline{W B C} \times 10^{9} / L$ & $7.93 \pm 2.68$ & $7.02 \pm 2.61$ & $7.83 \pm 2.62$ & $8.22 \pm 2.68$ & .246 & .018 & .580 \\
\hline $\mathrm{RBC} \times 10^{12} / \mathrm{L}$ & $4.58 \pm 2.34$ & $4.61 \pm 0.51$ & $4.86 \pm 4.78$ & $4.46 \pm 0.47$ & .836 & .927 & .475 \\
\hline $\mathrm{Hb}(\mathrm{g} / \mathrm{l})$ & $130.1 \pm 16.4$ & $136.5 \pm 15.9$ & $126.2 \pm 17.2$ & $129.7 \pm 15.8$ & .002 & .031 & .275 \\
\hline $\mathrm{HCT}(\%)$ & $40.07 \pm 4.15$ & $41.59 \pm 4.47$ & $38.92 \pm 4.47$ & $40.08 \pm 3.79$ & .002 & .061 & .126 \\
\hline $\mathrm{MCV}(\mathrm{fl})$ & $90.60 \pm 6.59$ & $90.26 \pm 5.68$ & $91.24 \pm 7.29$ & $90.45 \pm 6.56$ & .712 & .982 & .689 \\
\hline $\mathrm{MCH}(\mathrm{pg})$ & $29.32 \pm 2.72$ & $29.58 \pm 2.41$ & $29.53 \pm 3.16$ & $29.16 \pm 2.62$ & .995 & .615 & .618 \\
\hline MCHC \% & $32.33 \pm 1.35$ & $32.72 \pm 1.42$ & $32.30 \pm 1.51$ & $32.23 \pm 1.24$ & .229 & .070 & .934 \\
\hline RDW (\%) & $13.99 \pm 1.71$ & $13.25 \pm 1.22$ & $14.51 \pm 2.09$ & $14.01 \pm 1.59$ & .000 & .017 & .099 \\
\hline $\mathrm{PLT} \times 10^{9} / \mathrm{L}$ & $249.36 \pm 80.08$ & $267.62 \pm 100.89$ & $254.02 \pm 68.06$ & $242.39 \pm 77.29$ & 641 & .131 & .575 \\
\hline MPV (fl) & $9.62 \pm 1.37$ & $9.48 \pm 1.32$ & $9.60 \pm 1.61$ & $9.66 \pm 1.28$ & .888 & .708 & .957 \\
\hline Lymphocyte (\%) & $24.31 \pm 8.64$ & $28.42 \pm 10.68$ & $24.22 \pm 8.16$ & $23.18 \pm 7.84$ & .025 & .001 & .674 \\
\hline MID WBC (\%) & $7.57 \pm 2.34$ & $8.07 \pm 2.5$ & $7.11 \pm 2.12$ & $7.61 \pm 2.35$ & .986 & .863 & .707 \\
\hline Neutrophil (\%) & $67.72 \pm 9.17$ & $63.52 \pm 11.27$ & $67.91 \pm 8.33$ & $68.82 \pm 8.52$ & .028 & .001 & .766 \\
\hline
\end{tabular}

$P W$ pregnant women, $P<0.05$ is statically significant

MID WBC: which include Monocyte, eosinophile, basophile, and other midsized immature WBCs

is consistent with findings of Akinbami et al. (from $7.37 \pm$ 2.38 to $8.31 \pm 2.15$ ) [19], Das et al. (from $6.14 \pm 1.76$ to 8.09 \pm 4.12 ) [16], Osonuga et al. (from $6.22 \pm 1.79$ to $8.11 \pm 4.13$ ) [17] and Ifeanyi et al. (from $4.8+/-2.6$ to 7.81 $+/-1.7$ ) [18]. Physiologic stress induced by pregnancy [5] has been implicated as a possible mechanism for pregnancy associated leukocytosis. Besides, fetal immunity development pathways which include selective immune tolerance and modulation have also been suggested as possible explanations [20].

The finding of a significantly higher number of neutrophils in the second and third trimester pregnant women compared to the first trimester pregnant women in our study concurs with this scientific explanation. Neutrophils are the major type of WBC counts and their number can double during pregnancy compared to its postpartum values $[5,6]$.

In the present study, hemoglobin concentration and hematocrit values were highest in the first trimester, reach their lowest point in the second trimester and begin to raise again in the third trimester groups. This is consistent with a study conducted by James et al.

Table 3 Distribution of anemia by severity among the anemic pregnant women $(n=33)$, St. Paul's Hospital Millennium Medical College Addis Ababa, Ethiopia, 2014

\begin{tabular}{lll}
\hline Severity of anemia & Number & Percentage (\%) \\
\hline Mild anemia & 23 & 69.7 \\
Moderate anemia & 10 & 30.3 \\
Severe anemia & 0 & 0 \\
Total & 33 & 100 \\
\hline
\end{tabular}

$(\mathrm{Hb} 127.3 \pm 11.4114 .1 \pm 11.6, \& 116.7 \pm 11.8 \mathrm{~g} / \mathrm{l}$ and HCT $37.05 \pm 2.96,33.12 \pm 3.00$ and $34.03 \pm 2.97 \%$ for 1 st, 2 nd and 3rd trimesters respectively) [21] and Akinbami et al. $(32.07 \pm 6.80,29.76 \pm 5.21$, and $33.04 \pm 3.88 \%)$ [19] for hematocrit. While it contradicts with a study conducted by Ifeanyi et al. [18] and Osonuga et al. [17] in Nigeria which respectively showed low $\mathrm{Hb}$ and $\mathrm{HCT}$ in the first trimester, highest in the second trimester and drop in the 3rd trimester.

The decrease in hemoglobin concentration and packed cell volume from those in first trimester to those in second trimester may be due to hemodilution, hormonal changes, and increased iron demand $[6,16,19]$. Hormonal changes results production of rennin from kidneys to increase plasma volume during pregnancy. The increase

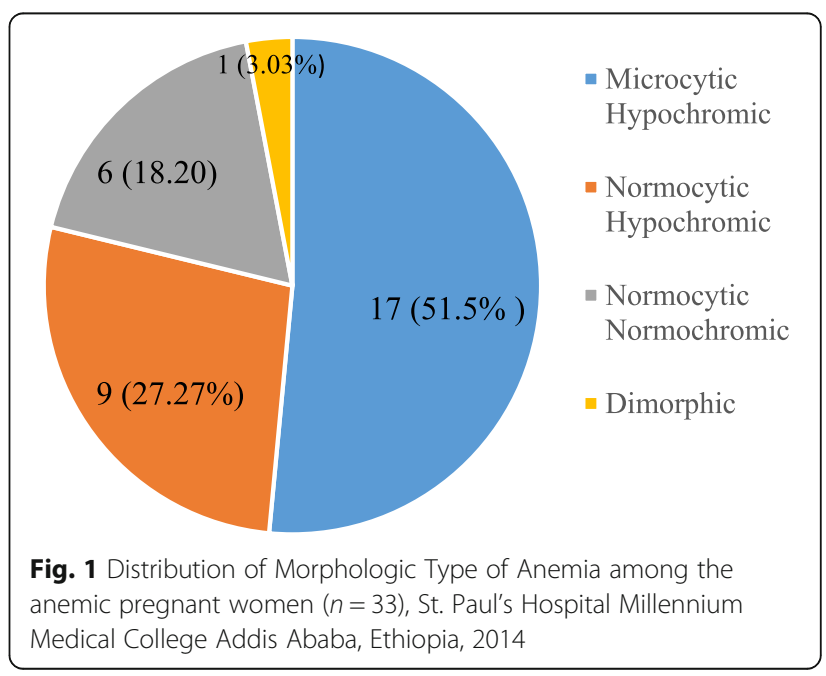


Table 4 Distribution of thrombocytopenia by severity among thrombocytopenic pregnant women $(n=22)$, St. Paul's Hospital Millennium Medical College Addis Ababa, Ethiopia, 2014

\begin{tabular}{lll}
\hline Severity & Number & Percentage (\%) \\
\hline Mild thrombocytopenia & 20 & 90.91 \\
Moderate thrombocytopenia & 2 & 9.09 \\
Severe thrombocytopenia & 0 & 0 \\
Total & 22 & 100 \\
\hline
\end{tabular}

in plasma volume is relatively greater than the increase in red cell mass, which results in a fall in maternal $\mathrm{Hb}$ and $\mathrm{HCT}$. In late pregnancy, plasma volume increases slowly that lead to a slight rise in hemoglobin and hematocrit value, it may account for the slight rise in $\mathrm{Hb}$ and $\mathrm{HCT}$ in the third trimester $[5,19]$.

Our study also reported a gradual reduction in PLT count as pregnancy advanced but the mean difference between the three trimesters was not statically significant. Our finding is similar with study conducted by Ajibola et al. [22], Akinbami et al. [19] and James et al. [21]. The reduction of platelet count as pregnancy advanced may be due to an increase in blood volume, increased platelet activation, and decreased life span in the uteroplacental circulation [5-7]. The present study also found an increment of mean platelet volume as the pregnancy advanced. This result is in agreement with a study conducted in Port Harcourt, Nigeria [23].

The finding of $11.62 \%$ anemia in this study is comparable to studies conducted in Iranian pregnant women (13.6\%), Nakhonsawan, Thailand (14.1\%), Sudaneese (10\%), and Ethiopian women from Hawassa (15.1\%), Gondar (16.6\%), and Debre Berhan (9.7\%) [24-29].

The result of the present study is much lower than studies conducted in Karantaka India (82.9\%), highlands of Tibet (ranges 41.3-77.9\%), Nepal (41.02\%), Uyo Nigeria (54.5\%), Jamaica (34.8\%), west Algeria (40.08\%), Uganda (63.1\%), Eastern Ethiopia (56.8\%), south west Ethiopia (53.9\%), and Arsi zone (Ethiopia) (36.6\%) [30-39]. Our result is also lower than results reported by studies in Turkey (27.1\%), Sokoto, Nigeria (21.3\%), and two other studies from Ethiopia namely Azezo in Gondar (21.6\%),

Table 5 Distribution of thrombocytopenia among pregnant women at different trimesters $(N=284)$, St. Paul's Hospital Millennium Medical College Addis Ababa, Ethiopia, 2014

\begin{tabular}{llll}
\hline Characteristics & \multicolumn{2}{l}{ Thrombocytopenia status } & Total \\
\cline { 2 - 3 } & Thrombocytopenic (\%) & Non-Thrombocytopenic (\%) & \\
\hline Trimester & & $46(95.8 \%)$ & 48 \\
1st trimester & $2(4.2 \%)$ & $62(93.9 \%)$ & 66 \\
2nd trimester & $4(6.1 \%)$ & $154(90.6 \%)$ & 170 \\
3rd trimester & $16(9.4 \%)$ & & \\
\hline
\end{tabular}

and Tikur Anbessa Specialized Hospital in Addis Ababa (21.3\%) [40-43].

The possible reason for the difference may be due to the differences in socio economic status, geographical variation and differences in dietary habits of the study participants. The lower result of our study may also be due to the Governments effort to achieve Sustainable Development Goals (SDGs).

The predominance of mild type of anemia in the current study fit well with studies conducted in Uyo Teaching Hospital Nigeria [33], Western Nepal [32], and studies conducted in different parts of Ethiopia: Tikur Anbessa Specialized Hospital [43], Debre Berhan Health Institutions [29], Southwest Ethiopia [38], and Gondar [28]. However, our result deviates from the findings from Karnataka India, west Algeria and Jimma (Ethiopia) which showed high rate of moderate Anemia [30, 35, 44].

The common morphological characteristic of anemia identified in our study, mainly microcytic hypochromic, and normocytic hypochromic, is deviated from studies conducted in Turkey [40], Northern Nigeria [45] and Gondar [28] which showed higher rate of normocytic normochromic type of anemia. Microcytic hypochromic and normocytic hypochromic blood picture are characteristic of iron deficiency anemia $[33,46]$, and our findings are in agreement with studies conducted in Sudan [47], Sokoto Nigeria [41], Uyo Nigeria [33], and New Delhi [46].

Thrombocytopenia is second to anemia as the most common hematologic abnormality encountered during pregnancy. The finding of $7.7 \%$ thrombocytopenia prevalence in the current study is similar to studies conducted in India (8.17\%) and (8.8\%), Iraq (8\%), and Ahmedabad (7.67\%) [48-51]. It also agrees with values indicated in a literature review conducted by Myers [15], which showed $8-10 \%$ rate of thrombocytopenia of all pregnancies. However, our result is lower than studies conducted in Ghana (15.3\%) and Nigeria (13.5\%) [22, 52].

The mildness of thrombocytopenia noted in the current study parallels findings from Iraq [51] Ghana, India, Nigeria, and Ahmedabad [22, 48, 49, 52]. The finding of predominantly mild thrombocytopeniamay be attributed to gestational thrombocytopenia (GT), which is of mild type and accounts for the majority of thrombocytopenias during pregnancy [7]. Though it is not associated with any adverse events for either the mother or baby and requires no specific treatment, other etiologies must be excluded (i.e. megaloblastic anemia, immune thrombocytopenia, eclampsia, and liver disorders) [6]. Especially, many features of GT are similar to mild immune thrombocytopenia and it can be difficult to distinguish between the two disorders [15].

The observed high prevalence of thrombocytopenia in the third trimester, which also agrees with other studies $[22,49,51,52]$, could be due to an increase in platelet 
aggregation especially during last 8 weeks of gestation. It has been reported that significant fall in platelet count can occur from 32 weeks of gestation onwards [6]. In the third trimester, platelet count decreases due to hemodilution, increased platelet activation and consumption [5].

\section{Conclusion}

In conclusion, in this study WBC, Hb, HCT, RDW, lymphocyte and neutrophil counts showed statistically significant difference between trimesters $(P<0.05)$. The prevalence of anemia and thrombocytopenia, both predominantly of mild type, were 11.62 and $7.7 \%$, respectively. Therefore, the pregnant women should be monitored and their hematological parameters properly interpreted to recognize and avoid pregnancy complications early. This will be of paramount importance in line with meeting the SDGs target related to maternal and child health.

\section{Additional file}

Additional file 1: Questionnaires. The data within additional file 1 contains questionnaires, which were used to collect information from the study participants for this study. The questionnaires had two parts; the first part is for collecting data about socio-demographic characteristics of the study subjects. The second part is for collecting complete blood count of the study participants. (DOCX $26 \mathrm{~kb}$ )

\section{Abbreviations}

ANC: Antenatal care; EDTA: Ethylene DiamineTetra Acetic acid;

GT: Gestational thrombocytopenia; Hb: Hemoglobin; HCT: Hematocrit; $\mathrm{MCH}$ : Mean cell hemoglobin; MCHC: Mean cell hemoglobin concentration; MCV: Mean cell volume; MPV: Mean platelet volume; PLT: Platelet; RBC: Red blood cell; RDW: Red cell distribution width; SDGs: Sustainable Development Goals; WBC: White blood cell; WHO: World health organization

\section{Acknowledgements}

We would like to thank Wollo University and Addis Ababa University for the financial and material support for this project. St. Paul's Hospital Millennium Medical College and ANC as well as hospital laboratory staffs are gratefully acknowledged for the support given to undertake this study in the hospital. Our special thanks and appreciation goes to all pregnant women who voluntarily participated in this study.

\section{Funding}

This study was funded by Addis Ababa University. The funder has no role in the design of the study and collection, analysis, and interpretation of data and in writing the manuscript.

\section{Availability of data and materials}

The data of this study can't be shared publicly due to presence of sensitive (confidential) participants' information and additional data than that used in this publication. But the data are available from the corresponding author on reasonable request.

\section{Authors' contributions}

$A G, D B$, and $A T$ involved in proposal writing, designed the study and participated in all implementation stages of the project. AG and AT also analyzed the data and finalized the write up of the manuscript. AG, DB and AT were responsible for critically revising the proposal and the manuscript. All authors reviewed and approved the final manuscript.

\section{Ethics approval and consent to participate}

The study obtained ethical approval from Departmental Research and Ethics Review Committee (DRERC) of the Department of Medical Laboratory
Sciences, Addis Ababa University (Protocol number: DRERC 092/14/MLS) and Institutional Review Board of St Paul's Hospital Millennium Medical College. Informed written consent was obtained from each voluntary participant prior to enrolment.

Consent for publication

Not applicable.

\section{Competing interests}

The authors declare that they have no competing interests.

\section{Publisher's Note}

Springer Nature remains neutral with regard to jurisdictional claims in published maps and institutional affiliations.

\section{Author details}

${ }^{1}$ Department of Medical Laboratory Science, College of Medicine and Health Science, Wollo University, Dessie, Ethiopia. 'Department of Obstetrics and Gynecology, Saint Paul's Hospital Millennium Medical College, Addis Ababa, Ethiopia. ${ }^{3}$ School of Medical Laboratory Science, College of Health science, Addis Ababa University, Addis Ababa, Ethiopia.

Received: 20 February 2018 Accepted: 25 June 2018

Published online: 09 July 2018

\section{References}

1. Carlin A, Zarko A. Physiological changes of pregnancy and monitoring. Best Pract Res Clin Obstet Gynaecol. 2008;22(5):801-23.

2. Datta S, Kodali BS, Segal S. Obstetric anesthesia handbook. 5th ed. Springer New York Dordrecht Heidelberg London; 2010.

3. Heidemann $\mathrm{BH}, \mathrm{McCl}$ re $\mathrm{JH}$. Changes in maternal physiology during pregnancy. Br J Anaesth. 2003;3(3):65-8.

4. Pavord S, Hunt B. The obstetric hematology manual. New York: Cambridge University Press; 2010. 278 p

5. Chandra S, Tripathi AK, Mishra S, Amzaru M, Vaish AK. Physiological changes in hematological parameters during pregnancy. Indian J Hematol Blood Transfus. 2012;28(3):144-6.

6. Kaur S, Khan S, Nigam A. Hematological profile and pregnancy: a review. Int J Adv Med. 2014;1(2):68-70.

7. Townsley DM. Hematologic complications of pregnancy. Semin Hematol. 2013;50(3):222-31.

8. WHO. Haemoglobin concentrations for the diagnosis of anaemia and assessment of severity [Internet]. Vitamin and Mineral Nutrition Information System: Geneva, World Health Organization; 2011 [cited 2016 Jul 17]. Available from: http://www.who.int/vmnis/indicators/haemoglobin. pdf.

9. WHO. Worldwide prevalence of anaemia 1993-2005: WHO global database on Anaemia. In: World Health Organization; 2008.

10. McLean E, Mary C, Egli I, Wojdyla D, de BB. Worldwide prevalence of anemia, WHO vitamin and mineral nutrition information system, 1993-2005. Public Health Nutr. 2008:1-11.

11. Allen LH. Anemia and iron deficiency: effects on pregnancy outcome. Am Soc Clin Nutr. 71:1280S-4S.

12. Mohammed AA, Elnour MH, Mohammed EE, Ahmed SA, Abdelfattah Al. Maternal mortality in Kassala state - eastern Sudan: community-based study using reproductive age mortality survey (RAMOS). BMC Pregnancy Childbirth. 2011;11:102

13. Rajasekhar A, Gernsheimer T, Stasi R, James AH. 2013 clinical practice quide on thrombocytopenia in pregnancy. American Society of Hematology; 2013.

14. Boehlen F. Thrombocytopenia during pregnancy Importance,diagnosis and management. Hamostaseologie. 2006;26:72-4.

15. Myers B. Thrombocytopenia in pregnancy. Obstet Gynaecol. 2009;11:177-83.

16. Das S, Char D, Sarkar S, Saha TK, Biswas S. Study of hematological parameters in pregnancy. IOSR J Dent Med Sci. 2013;12(1):42-4.

17. Osonuga I, Osonuga O, Onadeko A, Osonuga A, Osonuga A. Hematological profile of pregnant women in southwest of Nigeria. Asian Pac J Trop Dis. 2011:232-4

18. Ifeanyi OE, Ndubuisi OT, Leticia EOB, Uche EC. Haematological profile of pregnant women in Umuahia, Abia state. Nigeria IntJCurrMicrobiolAppSci. 2014;3(1):713-8. 
19. Akinbami AA, Ajibola SO, Rabiu KA, Adewunmi AA, Dosunmu AO, Adediran A, et al. Hematological profile of normal pregnant women in Lagos, Nigeria. Int J Women's Health. 2013;5:227-32.

20. Luppi P. How immune mechanisms are affected by pregnancy. Vaccine. 2003;21(24):3352-7.

21. James TR, Reid HL, Mullings AM. Are published standards for haematological indices in pregnancy applicable across populations: an evaluation in healthy pregnant Jamaican women. BMC Pregnancy Childbirth. 2008;8(8):1-4.

22. Ajibola SO, Akinbami A, Rabiu K, Adewunmi A, Dosunmu A, Adewumi A, et al. Gestational thrombocytopaenia among pregnant women in Lagos, Nigeria. Niger Med J. 2014;55(2):139-43.

23. Amah-Tariah F, Ojeka S, Dapper D. Haematological values in pregnant women in Port Harcourt, Nigeria II: serum iron and transferrin, total and unsaturated iron binding capacity and some red cell and platelet indices. Niger J Physiol Sci. 2011;26:173-8.

24. Barooti E, Rezazadehkermani M, Sadeghirad B, Motaghipisheh S, Tayeri S, Arabi $M$, et al. Prevalence of Iron deficiency Anemia among Iranian pregnant women; a systematic Reviewand meta-analysis. J Reprod Infertil. 2010;11(1):17-24.

25. Sukrat B, Suwathanapisate P, Siritawee S, Poungthong T, Phupongpankul K The prevalence of iron deficiency anemia in pregnant women in Nakhonsawan. Thailand J Med Assoc Thai. 2010;93(7):765-70.

26. Abdelgader EA, Diab TA, Kordofani AA, Abdalla SE. Haemoglobnin level, RBCs indices, and iron status in pregnant females in Sudan. Basic Res J Med Clin Sci. 2014;3(2):8-13.

27. Gies S, Brabin B, Yassin M, Cuevas L. Comparison of screening methods for anemia in pregnant women in Awassa, Ethiopia. Tropical Med Int Health. 2003;8(4):301-9.

28. Melku M, Addis Z, Alem M, Enawgaw B. Prevalence and predictors of maternal Anemia during pregnancy in Gondar. Northwest Ethiopia: An Institutional Based Cross-Sectional Study Hindawi Publ Corp Anemia. 2014;2014:1-9.

29. Ayenew F, Abere Y, Timerga G. Pregnancy Anaemia prevalence and associated factors among women attending ante Natal Care in north Shoa zone. Ethiopia Reprod Syst Sex Disord. 2014;3(3)

30. Viveki RG, Halappanavar AB, Viveki PR, Halki SB, Maled VS, Deshpande PS Prevalence of Anemia and its epidemiological determinants in pregnant women. Al Ameen J Med Sci. 2012;5(3):216-23.

31. Xing Y, Yan H, Dang S, Zhuoma B, Zhou X, Wang D. Hemoglobin levels and anemia evaluation during pregnancy in the highlands of Tibet: a hospitalbased study. BMC Public Health. 2009;9(336)

32. Singh $P$, Khan $S$, Mittal R. Anemia during pregnancy in the women of western Nepal. Bali Med J. 2013;2(1):14-6.

33. Olatunbosun OA, Abasiattai AM, Bassey EA, James RS, Ibanga G, Morgan A Prevalence of Anaemia among pregnant women at booking in the University of Uyo Teaching Hospital, Uyo, Nigeria. Hindawi Publ Corp BioMed Res Int. 2014;2014

34. Charles A, Campbell-Stennett D, Yatich N, Jolly P. Predictors of anemia among pregnant women in Westmoreland, Jamaica. Health Care Women Int. 2010;31(7):585-98.

35. Demmouche A, Khelil S, Moulessehoul S. Anemia among pregnant women in the Sidi Bel Abbes region (West Algeria) : an epidemiologic study. Blood Disord Transfus. 2011:2

36. Mbule M, Byaruhanga $Y$, Kabahenda M, Lubowa A. Determinants of anaemia among pregnant women in rural Uganda. Rural Remote Health. 2013;13:2259.

37. Alene KA, Dohe AM. Prevalence of Anemia and associated factors among pregnant women in an urban area of eastern Ethiopia. Anemia. 2014;2014

38. Getachew M, Yewhalaw D, Tafess K, Getachew Y, Zeynudin A. Anemia and associated risk factors among pregnant women in Gilgel gibe dam area,Southwest Ethiopia. Parasit Vectors. 2012;5(296)

39. Obse N, Mossie A, Gobena T. Magnitude of anemia and associated risk factors among pregnant women attending antenatal care in Shalla Woreda, west Arsi zone, Oromia region. Ethiopia Ethiop J Health Sci. 2013;23(2):165-73.

40. Karaoglu L, Pehlivan E, Egri M, Deprem C, Gunes G, Genc MF, et al. The prevalence of nutritional anemia in pregnancy in an east Anatolian province, Turkey. BMC Public Health. 2010;10:329.

41. Erhabor O, Isaac I, Isah A, Udomah F. Iron deficiency anemia among antenatal women in Sokoto, Nigeria. Br J Med Health Sci. 2013;1(4):47-57.

42. Alem M, Enawgaw B, Gelaw A, Kena T, Seid M, Olkeba Y. Prevalence of anemia and associated risk factors among pregnant women attending antenatal care in Azezo health center Gondar town, Northwest Ethiopia. Interdiscipl Histopathol. 2013:1(3):137-44.

43. Jufar AH, Zewde T. Prevalence of Anemia among Pregnant Women Attending Antenatal Care at Tikur Anbessa Specialized Hospital, Addis Ababa Ethiopia. J Hematol Thromboembolic Dis. 2014;2(1)

44. Desalegn S. Prevalence of anemia in pregnancy in Jima town, southwestern Ethiopia. Ethiop Med J. 1993;31(4):251-8.

45. Nwizu E, Iliyasu Z, Ibrahim S, Galadanci H. Socio-Demographic and Maternal factors in Anaemia in pregnancy at booking in Kano, Northern Nigeria. Afr J Reprod Health. 2011;15(4):33-41.

46. Gautam V, Bansal Y, Taneja D, Saha R. Prevalence of anemia amongst pregnant women and its socio demographic associates in a rural area of Delhi. Indian J Community Med. 2002;XXVII(4):157-60.

47. Elgari M. Evaluation of hematological parameters of Sudanese pregnant women attending at Omdurman Al Saudi maternity hospital. Egypt Acad J Biol Sci. 2013;5(1):37-42

48. Vyas R, Shah S, Yadav P, Patel U. Comparative study of mild versus moderate to severe thrombocytopenia in third trimester of pregnancy in a tertiary care hospital. NHL. J Med Sci. 2014;3(1):8-11.

49. Nisha S, Amita D, Pushplata S, Uma S, Tripathi AK. Prevalence and characterization of thrombocytopenia in pregnancy in Indian women. Indian J Hematol Blood Transfus. 2012;28(2):77-81.

50. Dwivedi P, Puri M, Nigam A, Agarwal K. Fetomaternal outcome in pregnancy with severe thrombocytopenia. Eur Rev Med Pharmacol Sci. 2012;16:1563-6.

51. Shamoon RP, Muhammed NS, Jaff MS. Prevalence and etiological classification of thrombocytopenia among a group of pregnant women in Erbil City. Iraq Turk J Hematol. 2009;26:123-8.

52. Olayemi E, Akuffo FW. Gestational thrombocytopenia among pregnant Ghanaian women. Pan Afr Med J. 2012;12(34)

\section{Ready to submit your research? Choose BMC and benefit from:}

- fast, convenient online submission

- thorough peer review by experienced researchers in your field

- rapid publication on acceptance

- support for research data, including large and complex data types

- gold Open Access which fosters wider collaboration and increased citations

- maximum visibility for your research: over $100 \mathrm{M}$ website views per year

At BMC, research is always in progress.

Learn more biomedcentral.com/submissions 